\title{
VOC EMISSIONS FROM URBAN MUNICIPAL SOLID WASTE DUMP SITES
}

\author{
Anjali Srivastava \\ National Environmental Engineering Research Institute, Kolkata, India
}

\begin{abstract}
Municipal solid waste management in India is becoming important in view of the fact that increasing amount of solid waste generated in most cities is now being recognized as a major public health problem. Poor management of solid waste leads to problems, which transcend traditional environmental boundaries and contribute to air, waters and soil pollution.

The percentage of India's population living in cities and urban areas has doubled to $28.8 \%$ by 2001 from $14 \%$ at the time of Independence, showing the rapid pace of urbanization. The progressively improved standards of living and the wasteful consumer attitudes have resulted in increase of quantities of municipal wastes to be handled.

The present system of solid waste management in India, like any other developing country, is fraught with many inadequacies. Illegal dumping is a major problem that raises significant concerns with regard to safety, property values, and quality of life in our communities. Poor collection or disposal practices are the problem. Since most cities in India still lack properly engineered landfills for safe disposal, waste here is mostly disposed in open dumps, which causes major environmental havoc.

Apart from other environmental hazards from open dumping of municipal solid waste, one of the major problems that rise are the uncontrolled emissions of VOCs or Volatile organic Compounds. VOCs are well known to be hazardous to human health and are potent carcinogens.

The present paper deals with qualitative and quantitative identification of VOCs from a two municipal waste dump site in Mumbai. Air at dump sites was sampled and analyzed on GC/MS in accordance with USEPA TO-17 compendium method for analysis of toxic compounds. As many as 20 VOCs were qualitatively identified and some VOC's were quantified. Concentration of Benzene was observed in the order of $0.6 \mathrm{ppm}$. Some of the VOCs identified were Hazardous Air Pollutants according to USEPA clean air act amendment of 1990.
\end{abstract}

\section{KEYWORDS}

VOC's, Municipal Solid Waste, emission.

\section{INTRODUCTION}

In India per capita municipal waste generation in major cities ranges from $0.2 \mathrm{Kg}$ to $0.6 \mathrm{Kg}$. Out of the total municipal waste collected, on an average $94 \%$ is dumped on land and $5 \%$ is composted. The mismanagement of solid waste in urban areas poses a grave threat to public health and the quality of life of people living in those areas. Up to now there has been no comprehensive policy in India that deals with the whole cycle of waste management from production at household level to collection and disposal. 
Mumbai, the commercial capital of India spans over 437.71 sq. $\mathrm{Km}$ and has a population of approximately 15 million. During the year 2000, MSW generated in greater Mumbai area was estimated as $6256 \mathrm{MT} / \mathrm{day}$. This waste is dumped at Deonar dump site and Malad dump site. Deonar dump site is located in the eastern suburb of Mumbai and is spread over an area of 132 ha. It receives approximately $4200 \mathrm{MT}$ of solid waste per day excluding construction and demolition waste. Malad Chincholi Bunder dump site is in western suburb of Mumbai.

Table 1.Waste Generation Rates, Composition and Characterisation of MSW in greater Mumbai.

\begin{tabular}{|c|c|}
\hline Population & $1,19,78,450$ \\
\hline Area & $437 \mathrm{Sq} . \mathrm{km}$ \\
\hline Waste & $6256 \mathrm{MTPD}$ \\
\hline Compostables & $62.44 \%$ \\
\hline Recyclables & $16.66 \%$ \\
\hline C/N Ratio & 39.04 \\
\hline HCV & $1786 \mathrm{Kcal} / \mathrm{Kg}$ \\
\hline Moisture & $54 \%$ \\
\hline
\end{tabular}

\section{Meteorology}

The city, being in the tropical zone and near the Arabian Sea, does not experience distinct seasons, but the climate can broadly be classified into two main seasons - the humid season and the dry season. Monthly relative humidity ranges between $57-87 \%$. The humid season, between March and October, is characterised by high humidity and temperatures of over $30^{\circ} \mathrm{C}$. The monsoon rains lash the city during June to September and supply most of the city's annual rainfall of $2,200 \mathrm{~mm}$.The dry season, between November and February, is characterised by moderate levels of humidity and warm to cool weather. Cold northerly winds are responsible for a high wind chill factor during January and February. The annual temperatures range from a high of $38^{\circ} \mathrm{C}$ to a low of $11{ }^{\circ} \mathrm{C}$. Table 2 summarizes monthly temperatures during 2003.

Table 2. Monthly Temperature at Mumbai for year 2003.

\begin{tabular}{|c|c|c|c|}
\hline Month & Minimum & Maximum & Average \\
\hline January & 15.2 & 33.8 & 15.2 \\
\hline February & 13.9 & 34.5 & 13.9 \\
\hline March & 18.7 & 35 & 18.7 \\
\hline April & 22.9 & 36.2 & 22.9 \\
\hline May & 25.1 & 36 & 25.1 \\
\hline June & 24 & 35 & 24 \\
\hline July & 23.5 & 31.9 & 23.5 \\
\hline August & 23.9 & 31.8 & 23.9 \\
\hline September & 23.5 & 31.3 & 23.5 \\
\hline October & 19.2 & 36.7 & 19.2 \\
\hline November & 19.1 & 37.4 & 19.1 \\
\hline December & 13.1 & 35 & 13.1 \\
\hline
\end{tabular}




\section{Methodology - Sampling and Analytical}

Methodology : Levels of VOCs in ambient air have been determined by adsorbing ambient air at a uniform flow rate on chromosorb 106 cartridge followed by thermal desorption and detection on Varian GC-MS in accordance with TO-17 compendium of methods for determination of toxic organic compounds (USEPA, 1999).

Battery operated personal air samplers were used to sample air at the rate of $20 \mathrm{ml}$ per minute through adsorption cartridge. Uniform flow rate was maintained using rotameter. The monitoring schedule followed 8 hourly samples during a day. Samples were collected at three locations on the dump site.

Sorbent cartridges were fabricated from stainless steel pipe (SS-316) having a length of $15 \mathrm{~cm}$ with internal diameter of $4 \mathrm{~mm}$ and external diameter of $6 \mathrm{~mm}$ with caps on both sides. Desorption from sorbent cartridge was carried out by heating at $200^{\circ} \mathrm{C}$ for 20 minutes. Two tubes were connected in series. When the concentration in the second tube was more than $5 \%$ of total concentration it was assumed that break through occurred.

As soon as the pump was turned off the cartridge were removed and capped tightly and sealed in plastic bags. The tubes were stored in refrigeration. Blank cartridges were also stored in identical condition.

Varian GC-MS (Model Saturn 3) with injection mode of sample introduction with DB 624 capillary column of $30 \mathrm{~m}$ length, $0.32 \mathrm{~mm}$ interval diameter and 1.8 microfilm was used. Helium gas with flow rate of $1 \mathrm{ml} / \mathrm{min}$ was used as carrier gas with split ratio $1: 25$, GC oven was programmed for $35^{\circ} \mathrm{C}$ hold for 2 min and ramped to $210^{\circ} \mathrm{C}$ with rate of $10^{\circ} \mathrm{C}$. Ion trap temperature was maintained at $125^{\circ} \mathrm{C}$ while maintained at $125^{\circ} \mathrm{C}$ while acquisition mass rage was from $35 \mathrm{amu}$ to $260 \mathrm{amu}$ in E1 model $100 \mu \mathrm{l}$ of desorbed sample was injected into the GC. Each peak of chromatogram was identified using NIST Library mass spectra for individual peak in the total ion chromatograph were examined with respect to fragmentation pattern of ions and $\mathrm{m} / \mathrm{z}$ for primary and secondary ions. First three mass abundances were matched to identify the peak. Some of the identified compounds were quantified using VOCMIX 15 of Dr. Ehrenstrofer from Perkin Elmer. Three sets of five point calibration curve were drawn and average curve was used to quantify the some of the identified VOCs which were also present in VOCMIX 15.

The distribution of HAPs in different component of environment, persistence and its long range transport potential has been calculated using a Multimedia Mass Balance Model, TaPL3.

The TaPL3 model divides the environment in several well-mixed compartments like atmosphere, sea, lake, sediment, soil, biota or vegetation, which are homogeneous, and in equilibrium. In the present study five number of compartment namely atmosphere, creek, soil, sediment, and vegetation have been considered. The environmental persistence of a chemical in the framework of the multimedia model calculation is defined as the average time a chemical resides in particular environment before it is degraded. Mathematically it is given by:

$T=n_{1} \sum \frac{M_{i}}{N_{i}} \sum\left(M_{1}^{*} K_{l}\right)$

Where, $\mathrm{T}$ is the overall persistence of chemical,

$\mathrm{n}_{1}$ is the number of compartment,

$\mathrm{M}_{\mathrm{i}}$ is the amount of chemical in compartment $\mathrm{i}$,

$\mathrm{K}_{\mathrm{i}}$ is the degradation rate in compartment $\mathrm{i}$. 
The potential for the chemical to be subject to Long-Range Transport is given by the characteristics Travel Distance in Air, LA $(\mathrm{Km})$

$$
L A=u * t A * Y A
$$

Where, $\quad \mathrm{u}(\mathrm{Km} / \mathrm{h})$ is the average wind speed, $\mathrm{tA}$ is the half life of the chemical in air $\mathrm{YA}$ is the mass fraction of the chemical in air

The average hoping value, $\mathrm{H}$, represents the average number of hops experienced by the chemical from one compartment to another. It is calculated only for emission to air. The average number of hop is calculated as,

$$
H=(N W, A+N S, A+N V, A) \frac{1}{E A}
$$

Where, NW,A is the transfer rate from water to air, NS,A is the transfer rate from soil to air, $\mathrm{NV}, \mathrm{A}$ is the transfer rate from vegetation to air, and EA is the emission rate to air, all in units of $\mathrm{mol} / \mathrm{h}$.

In the present study the environment has been considered as the study area with mixing height as the depth. TaPL3 has performed three simulations.

\section{RESULTS AND DISCUSSIONS}

Twenty VOCs have been identified in the emissions from dump sites. Amongst these eleven fall under the category of Hazardous Air Pollutants as defined in USEPA Air toxic programme. Figure 1 shows a typical chromatograph of an air sample from dumpsite. Table 2 shows the HAPs identified and their reactivity in the atmosphere. Species identified as highly reactive have atmospheric lifetimes of less than 6 hours under the specified typical annualaverage conditions. Those identified as medium-reactivity have a lifetime between 6 and 24 hours low-reactivity species have lifetimes between 1 and 60 days, and very low reactivity species have lifetimes greater than 60 days. High reactivity significantly decreases ambient concentrations. VOCs, which are highly reactive, thus exist in the atmosphere only close to their sources. As the reactivity decreases, effect on ambient concentrations is less, but longrange transport becomes an increasingly important factor. For the HAPs with very low reactivity, an anthropogenic background concentration exists that is the cumulative effect of global emissions. Amongst the VOCs identified Chloroform and Carbon Tetrachloride have very low reactivity and Methylene Chloride, Benzene, Toluene and Ethyl benzene have low reactivity. Naphthalene and Xylenes have medium reactivity and Styrene is highly reactive.

Under summer, daylight conditions, atmospheric lifetimes can be much shorter and conversely, under winter conditions the lifetimes can be longer. In tropical countries like India, it can be assumed that atmospheric reactivities will be higher as compared to western countries. The VOCs of concern from dumpsites are Chloroform, Carbon Tetrachloride Methylene Chloride, Benzene, Toluene and Ethyl benzene. Distribution of these VOCs in different components of environment is shown in Table 4. It is thus important to monitor them in gas phase. Figure 2 shows a typical output of TaPL3 model run. 
Table 3. HAPs from Dumpsite and their Atmospheric Reactivity.

\begin{tabular}{|l|l|l|l|l|}
\hline \multicolumn{1}{|c|}{ HAP } & Formula & \multicolumn{1}{c|}{ CAS.No } & Phase & Reactivity \\
\hline Methylene chloride & $\mathrm{CH}_{2} \mathrm{Cl}_{2}$ & 75092 & Gas & Low \\
\hline Chloroform & $\mathrm{CHCl}_{3}$ & 67663 & Gas & Very Low \\
\hline Carbon tetrachloride & $\mathrm{CCl}_{4}$ & 56235 & Gas & Very Low \\
\hline Benzene & $\mathrm{C}_{6} \mathrm{H}_{6}$ & 71432 & Gas & Low \\
\hline Toluene & $\mathrm{C}_{7} \mathrm{H}_{8}$ & 108883 & Gas & Low \\
\hline Ethylbenzene & $\mathrm{C}_{8} \mathrm{H}_{10}$ & 100414 & Gas & Low \\
\hline Naphthalene & $\mathrm{C}_{10} \mathrm{H}_{8}$ & 91203 & Gas & Medium \\
\hline Styrene & $\mathrm{C}_{8} \mathrm{H}_{8}$ & 100425 & Gas & High \\
\hline Xylene $(m)$ & $\mathrm{C}_{8} \mathrm{H}_{10}$ & 108383 & Gas & Medium \\
\hline Xylene $(o)$ & $\mathrm{C}_{8} \mathrm{H}_{10}$ & 95476 & Gas & Medium \\
\hline Xylene $(p)$ & $\mathrm{C}_{8} \mathrm{H}_{10}$ & 106423 & Gas & Medium \\
\hline
\end{tabular}

Table 4. Percentage distribution of VOCs in Different Environments.

\begin{tabular}{|r|r|r|r|r|r|}
\hline \multirow{2}{*}{ VOC } & \multicolumn{6}{|c|}{ Percentage in Environment } \\
\cline { 2 - 6 } & \multicolumn{1}{|c|}{ Air } & \multicolumn{1}{|c|}{ Water } & \multicolumn{1}{c|}{ Soil } & Sediment & Vegetation \\
\hline Benzene & 98.2 & 0.0005 & 1.8 & 0.0004 & 0.003 \\
\hline Carbon Tetrachloride & 90.0 & 0.0005 & 4.98 & 0.87 & 4.15 \\
\hline Ethyl benzene & 0.013 & 0.00002 & 1.34 & 0.035 & 98.6 \\
\hline Styrene & 95.4 & 0.0003 & 0.22 & 0.003 & 4.4 \\
\hline Toluene & 96.2 & 0.0001 & 1.35 & 0.002 & 2.41 \\
\hline Xylene & 0.07 & 0.00008 & 6.44 & 0.14 & 93.4 \\
\hline Naphthalene & $2.28 \mathrm{E}-07$ & $3.85 \mathrm{e}-12$ & $1.01 \mathrm{E}-08$ & $6.82 \mathrm{E}-09$ & 100 \\
\hline
\end{tabular}

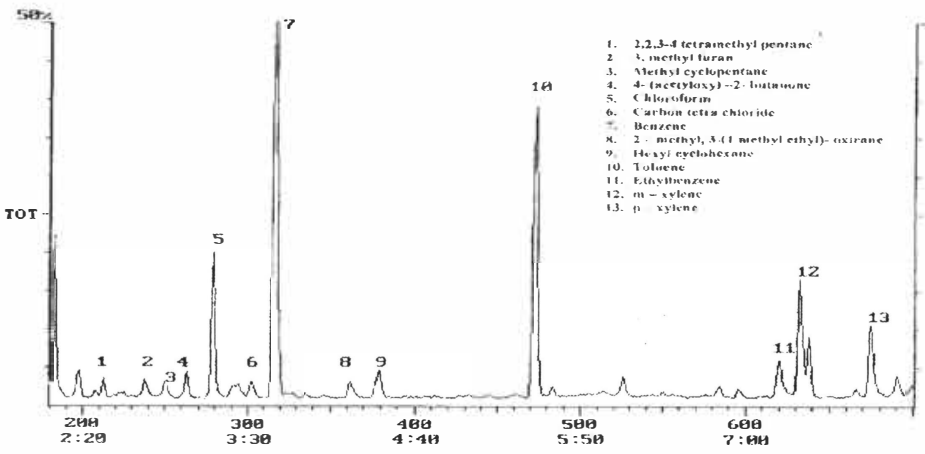

Figure 1. Typical chromatograph of an air sample from municipal dumpsite. 


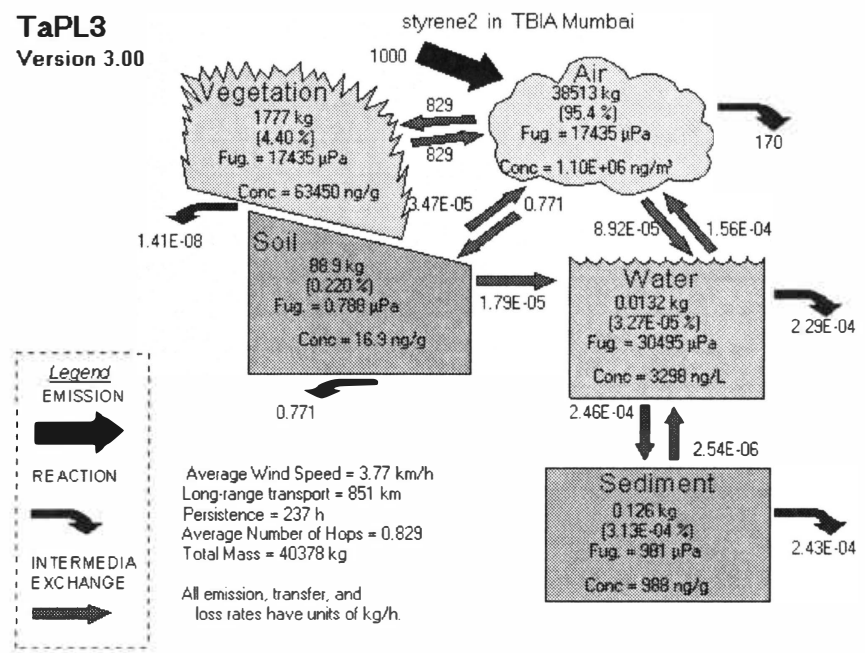

Figure 2. TaPL3 out for distribution of Styrene in environment.

\section{REFERENCE}

[1] Status of Municipal Solid Waste: Generation Collection Treatment and Disposal in Class I cities, CPCB April 2000.

[2] Manual on Municipal Solid Waste Management (first edition). Prepared by The Expert Committee constituted by the Ministry of Urban Development, The Government of India. January 2000.

[3] Urban Waste: Status, trends and interventions. Ravi Agarwal, Srishti, January 2001. Personal Communication with Dr AK Tripathy, Ministry of Non-conventional Sources.

[4] Beyer, A., Mackay, D., Matthies, M., Wania , F., Webster, E. 2000. Assessing long range transport potential of persistence organic pollutants. Environ Sci Technol 699703.

[5] Mackey D. 1979. Finding Fugacity Feasible. Environ Sci Technol., 1218-1223.

[6] NEERI (National Environmental Engineering Research Institute) Report, 2005. Monitoring and Inventory of emission of volatile organic compounds in urban air Phase II. Submitted to Central Pollution Control Board, Delhi.

[7] Shonnard David R., Alex S. Mayer, Kurtis G. Paterson, and Martin T. Auer, 1996. Environmental Fate and Risk Assessment Tool (EFRAT); Michigan Technological University.

[8] TRIMFaTE 1999a. USEPA, Office of air quality Planning and standards. TRIMFaTE technical support document, Description of module. EPA-453/D-99-002A, vol. I. Research Triangle park, NC

[9] TRIMFaTE 1999b. USEPA, Office of air quality Planning and standards. TRIMFaTE technical support document, Description of chemical transport and transformation algorithm. EPA-453/D-99-002B, vol. II. Research Triangle park, NC

[10] USEPA, 1999. Compendium Methods for the Determination of organic compounds in ambient air, TO-17, EPA625/R-96/-010b. 
[11] Webster E., Mackey, D., Wania, F. 1998. Evaluating environmental persistence. Environ Toxicol Chem , 2148-2158.

[12] Webster, E., Hubbarde, J., Mackay, D., Swanston, L., Hodge, A., 2003. Development of Tools to improve Exposure estimation for use in ecological Risk Assessment: The TaPL3 upgrade. Report to environment Canada. CEMC Report 2003xx. Trent University, Peterborough, Ontario. 